\title{
The Causal Relationship between Socioeconomic Status and Smoking Behavior: Evidence from Canada
}

\author{
Wang Pengyu ${ }^{1}$, a \\ ${ }^{1}$ Huron University College at Western \\ apwang266@uwo.ca
}

Keywords: socioeconomic status, smoking behavior, probit model, empirical analysis

\begin{abstract}
I will be analyzing information related to health status in Canada to determine the causal relationship between socioeconomic status and smoking behavior by using the probit model. The data set used includes information from the Canadian Community Health Survey on Canadians 12 years and older with a focus on the following factors influencing smoking behaviors: highest level of education achieved, and total personal income. Results of this survey show that the most significant influences behind taking up smoking were low income and low education. The results from the empirical analysis show that those most likely to smoke are single, middle aged males with low income and a low education level. In the expanded model, I found that within the same income level, if an individual's education level is higher, the probability to smoke will decrease. Finally, some policy advices are given out.
\end{abstract}

\section{Introduction}

Nowadays, people's health condition has been highlighted more than ever as the development of the economy. Cancer, the most threat to people's health, has been a severe problem in the modern society. Amid all unhealthy habits in today's world, smoking is one of the most flagrant penchants that cause cancers and other health problems.

Numerous academic researchers in many medical fields, such as lung cancer, cardiovascular diseases, etc., have suggested that smoking behavior casts substantial impacts on human's health situation. How serious and austere the situation is now? It is reported that one fifth of mortality in Canada is smoking-related (Canadian Cancer Society's Advisory Committee, 2014). Furthermore, tobacco use catalyzes $85 \%$ of lung cancers, and smokers suffer an over 20 times larger probability of lung cancer than non-smokers (Canadian Cancer Society, n.d.). Not only by these, smoking also leads to many other cancers, including cancers of the larynx, oral cavity and pharynx, esophagus, and bladder. Smoking is also a main catalyze to heart diseases, stroke, and respiratory illness (Smoking and Lung Cancer in Canada, 2010). Considering the huge detrimental healthy impact of smoking on people's life wellbeing, governments have devoted to control the use of tobacco and guided people not to smoke that much.

Significant gains have been reached in regulating and controlling the tobacco industry and its whole supply chain in North America and other countries. However, smoking rate remains high for the general adult population. In 2015, North American Tobacco Market contributed about 60 billion dollars income, which is still in a very large scale (WHO Report on the Global, 2015). In Canada, 5.8 million of Canadians, whose age are older than 12, are smokers, almost one in six, with the country's total population about 36.2 million (Statistics Canada, 2016). In 2015, Canadian contributes 9.3 billion dollars in tobacco market, which means in average, each smoker spends approximately 
$\$ 1,800$ a year (WHO Report on the Global, 2015). With a 35-pack costing $\$ 12$ in retail, this means each smoker consumes 15 cigarettes per day. Both the total number and individual expenditure are large enough to be worrisome.

The traditional tobacco controlling methods are increasing tobacco taxation; limiting product packaging as well as target customers in retail and forbid smoking in public area and indoor. These methods do have positive effect which makes the smoker number decrease $20 \%$ compared to ten years ago in 2005 (WHO Report on the Global, 2015). On the other hands, total tobacco industry income keeps the same level, even increased modestly in recent years. Now we see a problem, without counting the increase of tobacco taxation, previous result means that fewer smokers spend more money on tobacco and consume more cigarettes individually. This gives us a sense that the traditional tobacco controlling methods is good at preventing new smokers but show very limited effect on existed smokers.

For these existed smokers, expenditures are much more than the amount purely spent on purchasing cigarette, there are some associated costs due to smoke. According to another study, life insurance expense is more than twice for smokers than non-smokers, a cost that triples after the age of 50 (Cost of Smoking, 2014). What's more, it is shown that the annual health care cost per smoker is $\$ 3,071$, much higher than non-smokers (Bradley, 2015). On the other side, the employers endure some economic costs of employees that smoke. Taking smoking breaks during work hours and increased absenteeism due to smoking costs Canadian companies an average of $\$ 230$ per smoker per year, with an extra $\$ 85$ per person for the cost of building the smoking areas.

Based on these facts, besides nicotine addiction, how a person's socioeconomic status can affect his/her smoking decision is the major concern that I want to investigate. Further, I would like to indicate some policy recommendations for better control of smoking and to enhance the overall healthy condition for citizens and their wellbeing as well.

There are a few significances of considering socioeconomics and smoking behavior. At the market side, quantitative result of consumer behavior will help tobacco companies have a sense of their customers' distribution and status, this may support tobacco companies reorganize and adjust their strategies, products and advertisements. At the government side, clearly knowing smokers' socioeconomics can help them make wiser and flexible policy to manage and control tobacco industry. At the same time, it can also help the government pushing targeted publicity in banning smoking behavior.

The academic world is quite curious about the underlying reasons for one's smoking behavior for figuring out an effective way to control the abusive tobacco consumption and enhancing the living standards in the end. There are numerous of published researches conducted by other groups, which establish models to analysis problems that are similar to my concerns, and provide with their conclusions and explanations.

A Multiple Regression Analysis is run on an Analytic Hierarchy Process Model, focus on the impact of social class and residence on smoking behavior (Cummins, et al., 1983). They quote the social class into 6 level according to General's 1970 classification, which overall consider income, career, number of children and per capita residential area. The result shows there is a strong relationship between smoking and social class, especially in women's social class. However, the social class level in their research is a comprehensive index, which is affected by different independent or related variables. They didn't consider these variables. 
Quadratic and cubic functions fitting in logistic regressions model is used to investigate the problem about smoking in Scottish youths with controls of personal income, parental social class and the cost of smoking. Their results show strong independent effects of parental social class and personal income, both reducing with age (West, P., et al., 2007). Logistic regressions model is quite proper with analyzing independent variables. However, their variable scale is small, and the target of their research is only focus on high school students, this limits the reference value of their results.

Another research conducts a regression analysis using Multi-Level Logistic Regression Method, with data from Netherlands over 2004 to 2011 with a total sample of 66960. They introduce age, marital, neighborhood educational level and income as variables and give proper deviation groups for each variable (Benson, et al., 2015). Their analyzing flow and variable chosen standard are very meaningful to this research. However, they didn't analysis the interaction for different variables.

A group that is often overlooked in studies, but is important to understanding why people take up smoking, is the homeless, whose socioeconomic status is extremely low. Homelessness makes individuals much more likely to start smoking. It is estimated that $70-99 \%$ of the homeless adults' smoke, versus only $22 \%$ of the world adult population previously mentioned (Socioeconomic Status: The Single Greatest, 2008). The homeless experience high stress, and often feel vulnerable and lonely. Cigarettes are used as a tool for individuals in low socioeconomic status to cope with stress, as well as a partner for alcohol and caffeine. Education material is also not as widely integrated for this segment, and often members of this population live in communities where tobacco advertising is more prominent. Those who work in industries that are generally deemed as for lower income individuals or the less educated such as manufacturing, construction, or transportation are more likely to be exposed to secondhand smoke at work, and, therefore, start smoking themselves (Socioeconomic Status: The Single Greatest, 2008).

The previous studies offer us some insights and inspirations for the further research. In this study, a probit regression model is established to process the estimation with a larger stress on the socioeconomic status, ensuring the causal relationships to be well investigated and interpreted. The dataset is from academic data resources with large enough scale and high reliability.

I have also overcome a problem of discrete data. Many well-designed and reliable datasets are using categorical variables to collect data, which will make it hard to conduct a regression analysis. In this study, I solve this problem by setting multiple binary variables based on good reasonings. A better methodology, more enriched interpretations and a rigorous logic flow will provide readers with a better sense of the fundamental motivation for an individual's smoking decision. In the end, my study proposes policy advices and economic mechanisms to control the tobacco use, which is another prominent contribution in this paper.

In the first part, I have introduced related background knowledge, some important data collected from academic resources, at the same time, carefully think about previous studies by other groups. In the next part, I would like to come up with some basic theoretical thought. In part three, I will exhibit our data base and how the data is refined for this study. In the fourth section, three models are established successively, with their variable scale and complexity increased, and the results will be explained. Finally, in the fifth part, I will conclude the findings and explanations. Based on that, I will also provide with some policies that may solve the difficulties in reducing tobacco consumption. 


\section{Fundamental Theory}

The initial theoretical thought is based on a fundamental economic theory: the consumer theory with the consideration of both the income effect and the substitution effect. If we assume that tobacco is a normal good, then the tobacco consumption will increase as the income increases. If tobacco is considered to be an inferior good, the tobacco use will decrease as income increases. I actually expect that smoking will be a normal good at first, and then become an inferior good as income level rises, which implies an initially upward sloping and finally backward bending Engel curve. In addition, we also think that a person with higher income and educational background will know better about the pernicious impact of smoking and more likely to consider it as an inferior good.

If we consider more about a life-cycle hypothesis and an intertemporal utility function (considering tobacco consumption and health), taking smoking habit as a potential income and health risk faced by the individual, then we can set up a model as the following:

$$
\operatorname{Max} U_{1}\left(C_{T 1}, H_{1}, C_{1}\right)+\beta U_{2}\left(C_{T 2}, H_{2}, C_{2}\right)
$$

Note: $\mathrm{U}_{1}=$ the utility of period 1 (young), $\mathrm{U} 2=$ the utility of period 2 (old)

$\mathrm{C}_{\mathrm{Ti}}=$ the tobacco consumption at period $\mathrm{i}, \mathrm{i}=1,2$

$\mathrm{C}_{\mathrm{i}}=$ the other consumption by the individual at period $\mathrm{i}, \mathrm{i}=1,2$

$\mathrm{H}_{\mathrm{i}}=$ the demand of health at period $\mathrm{i}, \mathrm{i}=1,2$

$\beta$ is the discount parameter.

As shown above, in an intertemporal utility function (2-period), considering only the consumption of the tobacco and the need for health, an individual always wants to maximize his/her lifetime utility. The individual tends to consume more tobacco as he/she is young with a higher income level and lower healthy risks, assuming that the youth are less worry about their health condition as well. However, they may choose to smoke less when they are getting old with a lower income level, for they will be more vulnerable under the influence of smoking, and their preference over tobacco consumption and health has also changed. At the same time, they also want to attenuate their healthy cost and healthy risk to uphold their elder age consumption (for other goods), which also leads to abatement in tobacco use. Therefore, I expect a hump shaped curve for an individual's tobacco consumption overtime.

\section{Data Description}

The metadata I used in the models are taken from Canadian Community Health Survey (CCHS) 2014 from Statistics Canada. CCHS 2014 is a cross sectional survey collecting data on health status and health determinants for the Canadian population.

As they noted, CCHS collected data mainly in categories, which means most of the dataset will be discrete. For example, they put personal yearly disposable income into six categories: no income, less than $\$ 20000, \$ 20000$ to $\$ 39999, \$ 40000$ to $\$ 59999$, $\$ 60000$ to $\$ 79999$, and over $\$ 80000$. For simplification, I decide to compress some of the categories. For instance, I cut down the categories for income from 6 to 3, reduce the 16 age categories to 3 age groups, change 4 marital status groups to a binary variable, lessen 6 educational groups to 3, and etc. All contraction decisions are delicately refined, and the new categories are more fit to the following regression, considering simplicity and reasonability. The reason why I reset categories like that will be illustrated in the next part successively. 
Table 1 Data Description

\begin{tabular}{l|lllll}
\hline Variables & Observations & Mean & Std. Dev. & Min & Max \\
\hline Y & 49386 & 0.1944 & 0.3958 & 0 & 1 \\
Age1 & 49386 & 0.0717 & 0.2581 & 0 & 1 \\
Age2 & 49386 & 0.6071 & 0.4884 & 0 & 1 \\
Age3 & 49386 & 0.3212 & 0.4669 & 0 & 1 \\
Inc1 & 49386 & 0.2756 & 0.4468 & 0 & 1 \\
Inc2 & 49386 & 0.4848 & 0.4998 & 0 & 1 \\
Inc3 & 49386 & 0.2396 & 0.4268 & 0 & 1 \\
Edu1 & 49386 & 0.1742 & 0.3793 & 0 & 1 \\
Edu2 & 49386 & 0.2024 & 0.4017 & 0 & 1 \\
Edu3 & 49386 & 0.6234 & 0.4845 & 0 & 1 \\
Sex & 49386 & 0.4430 & 0.4967 & 0 & 1 \\
MRS & 49386 & 0.5327 & 0.4989 & 0 & 1 \\
Alch & 49386 & 0.7884 & 0.4084 & 0 & 1 \\
\hline
\end{tabular}

Table-1 above shows all the categories we have in the following regression analysis. In the table the Mean and Standard Deviation are shown for each group created.

In the table, $\mathrm{Y}$ is the dependent variable in my study. $\mathrm{Y}$ equals to 1 means that the person is a daily or occasionally smoker, 0 means the individual is a non-smoker. Incl means low-income level; Inc2 means mid-income level; Inc3 means high-income level. Edu1 means low-education level; Edu2 means mid-education level; Edu3 means high-education level. Age1 means youth (12 to 24 years old); Age2: means adults (25 to 64 years old); Age 3 means seniors (65 years old and above). Sex is the gender dummy (Male=1); MRS is the marital status dummy (1= married or common law); Alch refers to the alcohol use dummy ( $1=$ alcohol used in the past 12 months). In all groups above, when the dummy value equals to 1 , it means the individual belongs to that group, other than the value equals to 0 . On what criterion and theoretical thought the above groups are based will be further illustrated in the modeling part.

From the Table-1, we can observe that near $20 \%$ of the Canadian people in the sample are smokers. Middle-aged population captures the largest sector. Near half of the Canadians in the sample earn a middle-income level. Over $60 \%$ of observations are well-educated. Most of the people in the sample have alcohol use in the past 12 months and over half of them are married or live in common-law.

\section{Modeling and Result Interpretation}

The causality between smoking behavior and socioeconomic factors with a special focus on income was investigated. This causal relationship is of importance for future policy making decisions, as government officials could use the results in implementing prevention policies. For the purposes of the survey and this analysis, a smoker is an individual who smokes daily or occasionally at present time.

Although there are many factors contributing to people using tobacco, I consider the socioeconomic status to be the biggest predictor. Socioeconomic status (SES) is defined as an 
individual's or a group's position within a hierarchical social structure. Socioeconomic status depends on a combination of variables, including occupation, education, income, wealth, and place of residence. Sociologists often use socioeconomic status as a means of predicting behavior (The American Heritage ${ }^{\circledR}$ New Dictionary, 2005).

However, some questions are necessary to think beforehand: which variables should be chosen as independent variables and involved in my regression? How can we avoid the omitted variable bias? And how we can solve for the interactive effects among variables.

Table 2 Regression Results

\begin{tabular}{|c|c|c|c|}
\hline Variables & Benchmark (1) & Expanded (2) & Further study (3) \\
\hline Inc1 & $\begin{array}{c}0.276^{* * *} \\
(15.16)\end{array}$ & $\begin{array}{c}0.379 * * * \\
(17.89)\end{array}$ & $\begin{array}{c}0.420 * * * \\
(16.16)\end{array}$ \\
\hline Inc2 & $\begin{array}{c}0.114 * * * \\
(6.84)\end{array}$ & $\begin{array}{c}0.201 * * * \\
(11.19)\end{array}$ & $\begin{array}{c}0.0776^{* * *} \\
(1.19)\end{array}$ \\
\hline Sex & & $\begin{array}{c}0.204 * * * \\
(14.72)\end{array}$ & $\begin{array}{c}0.203 * * * \\
(14.58)\end{array}$ \\
\hline MRS & & $\begin{array}{c}-0.331 * * * \\
(-23.27)\end{array}$ & $\begin{array}{c}-0.331 * * * \\
(-23.29)\end{array}$ \\
\hline Alch & & $\begin{array}{c}0.189 * * * \\
(10.69)\end{array}$ & $\begin{array}{c}0.190 * * * \\
(10.7)\end{array}$ \\
\hline Age1 & & $\begin{array}{c}0.340 * * * \\
(11.53)\end{array}$ & $\begin{array}{c}0.346 * * * \\
(11.7)\end{array}$ \\
\hline Age2 & & $\begin{array}{c}0.695 * * * \\
(39.87)\end{array}$ & $\begin{array}{c}0.694 \\
(39.77)\end{array}$ \\
\hline Edu1 & & $\begin{array}{c}0.385 * * * \\
(19.71)\end{array}$ & $\begin{array}{c}0.490 * * * \\
(7.79)\end{array}$ \\
\hline Edu2 & & $\begin{array}{c}0.225 * * * \\
(13.22)\end{array}$ & $\begin{array}{c}0.373 * * * \\
(9.59)\end{array}$ \\
\hline Incedu 11 & & & $\begin{array}{l}-0.0888 \\
(-1.29)\end{array}$ \\
\hline Incedu 12 & & & $\begin{array}{c}-0.223 * * * \\
(-4.48)\end{array}$ \\
\hline Incedu 22 & & & $\begin{array}{c}0.00756 \\
(0.1)\end{array}$ \\
\hline Incedu 23 & & & $\begin{array}{c}0.164 * \\
(2.4)\end{array}$ \\
\hline Cons_ & $\begin{array}{c}-0.998 * * * \\
(-71.93)\end{array}$ & $\begin{array}{c}-1.745^{* * *} \\
(-61.32)\end{array}$ & $\begin{array}{c}-1.772 * * * \\
(-60.83)\end{array}$ \\
\hline Pseudo-R ${ }^{2}$ & 0.0050 & 0.0630 & 0.0636 \\
\hline
\end{tabular}

Note: $T$-statistics in parentheses, ${ }^{*}$ value $<0.1,{ }^{* *}$ value $<0.05,{ }^{* * *}$ value $<0.01$

Benchmark Model. When we talk about socioeconomic status, income level is the most directly and significant criterion of judgment. Income level is a strong predictor of smoking habits. In this model, 
the dependent variable, Y, represents "smoking status" and will be used as a dummy variable. When $\mathrm{Y}$ equals to 0 , it means that the person is not a smoker at all, if it equals to 1, it means that the person smokes daily or occasionally at present time. Based on the collected data, I have separated "income" into three categories, which are "low-income", "mid-income", and "high income". For people in low-income groups, their earnings are less than $\$ 20,000$ a year. For people with high income, their earnings are over $\$ 60,000$ a year. For people who earns $\$ 20000$ to $\$ 60000$ is in mid-income level. I expect that when peoples' income is the only variable that affects their cigarette use, people with higher income have a smaller probability to smoke. Sub income levels into probit model correlation, then we get:

$$
P_{r}\left(Y_{i}=1\right)=\Phi\left(\beta_{0}+\beta_{1} \operatorname{Inc1}_{i}+\beta_{2} \operatorname{Inc} 2_{i}+u_{i}\right), i=1,2,3 \ldots
$$

Note: Inc1: low-income level; Inc2: mid-income level; Inc3: high-income level

Column (1) shows that income has a strong causal effect on people's probability to smoke, and people that have the lowest income have the highest probability to smoke. If a person belongs to a low-income group, his/her probability to smoke is $23.89 \%$. For a person who belongs to a midincome group, his/her probability to smoke is $18.94 \%$. Similarly, people with high income have a $15.87 \%$ of probability to smoke.

This is logical, because people with higher income tend to pay more attention to their health and life quality, as more resources are available to them to do so. Besides, since tobacco is an inferior good in higher income levels, tobacco consumption falls as income rises, the wealthy consume less tobacco than the poor (Peck, 2002). Moreover, like previously mentioned, tobacco companies strategically advertise more in neighborhoods with lower income (Humphreys, 2008). However, the Pseudo- $\mathrm{R}^{2}$ of this model is very low, which implies that income alone cannot explain people's smoking behavior well.

Expanded Model. The benchmark model can easily cause omitted variable bias because there exist other socioeconomic indicators. Therefore, in the second model, people's education level is added to eliminate omitted variable bias. People's education level is set as three categories, which are 'less than secondary', 'secondary education' and 'post-secondary education'. I have also included four more control variables, which are people's 'age', 'sex', 'marital status', and 'alcohol use in the last 12 months' into the model. All of these four new variables are dummy variables. For people's age, I divided it into three categories, which are 'children and youth', 'adults' and 'seniors' according to Statistics Canada. For people's gender, I set it equal to 1 if the person is a male. For people's marital status, I set this dummy to be 1 if the person is married or live in common-law. For alcohol use, if a person has drunk regularly in the last 12 months, then the value of this dummy is 1 . It is expected that all these variables have a significant causation on people's smoking behavior. And I expect that an unmarried, low-educated, middle- aged male who has drunk in the last 12 months will be more likely to be a smoker. Therefore, an expanded model can be set up as:

$P_{r}\left(Y_{i}=1\right)$

$$
\begin{aligned}
& =\Phi \\
& \left(\beta_{0}+\beta_{1} I n c 1_{i}+\beta_{2} I n c 2_{i}+\beta_{3} E d u 1_{i}+\beta_{4} E d u 2_{i}+\beta_{5} A g e 1_{i}+\beta_{6} \operatorname{Age2}_{i}+\beta_{7} \operatorname{Sex}_{i}+\beta_{8} M R S_{i}\right. \\
& \left.+\beta_{9} A_{l c h}+u_{i}\right), i=1,2,3 \ldots
\end{aligned}
$$

Note: Edu1: low-education level; Age1: youth (12 to 24 years old);

Edu2: mid-education level; Age2: adults (25 to 64 years old);

Edu3: high-education level; Age3: seniors (65 years old and above) 
Sex: the gender dummy; MRS: the marital status dummy; Alch: the alcohol use dummy

The results for extended model are listed in column (2). These coefficients show that all socioeconomic indicators were significantly associated with smoking under the $95 \%$ significance level.

In terms of education. a higher educational level will decrease an individual's probability to smoke significantly. This can be explained in three ways. Firstly, a well-educated person knows better about the negative effects of smoking. Thus, his/her probability to quit smoking will be higher (Koning, et al., 2015). Secondly, if we consider education as an investment, more education refers to more income in the future, which means a higher consumption level in the future. Because of this, the person who receives a higher level of expected utility in the future will have more incentives to stay healthy (Walque, 2006). Finally, a better educational level provides people with a better job with more satisfactory circumstance, which means the probability that you are exposed to second-hand smoke will be smaller, and decrease the probability to smoke as a result.

Among all other variables, marital status is the only one that has a negative coefficient, which means that a person who is married will have a lower probability to smoke. It can be explained that wives and husbands seem to discourage their partners from acting in a way that is harmful to their overall health (Adshade, 2014). What's more, since households' incomes are always fixed (in shortrun), more expenditure on tobacco will decrease household expenditures on other goods like food, education, and healthcare. For married people, they receive a larger expected expenditure on children's education or their partner's expenses. Therefore, married people always smoke less because their changes in expenditure patterns (Young, et al., 2015).

Also, I found that adults have the most probability to smoke among all the three age categories and seniors have the least. It can be explained logically as adults usually experience the highest level of stress, in comparison to youth and the elderly. It is because the adults usually have the largest financial burden in a family. This age group experiences the most pressure to pay bills, and usually undertakes stressful life decisions revolving around loans and mortgages. It is also that seniors tend to start paying closer attention to their health, as they become older and naturally sicker. We also found that males smoke more tobacco than females. The reason is that tobacco industries market a lot more to males. This is also due to more acceptance of smoking for males versus females in our society (Hitchman, et al., 2011).

Moreover, based on the research of the National Institute on Alcohol Use and Alcoholism, a drinker often more tends to smoke. Several mechanisms may contribute to concurrent alcohol and tobacco use, including genes that are involved in regulating certain brain chemical systems; neurobiological mechanisms; conditioning mechanisms; and psychosocial factors. Because of those reasons, a drinker has a higher probability to smoke (Drobes, 2002).

Further Study. From the expanded model above, I tried to eliminate the omitted variable bias by introducing an individual's educational level. However, I realized that the effect of an individual's income on smoking behavior depends on his/her educational level, since people who have higher educational level tend to be subjected towards more educational material regarding smoking and its health risks. This means income level and education level are not independent with each other which will cause inaccuracy in regression analysis. This is our third question mentioned at the beginning of this part.

To solve this problem, I introduced some interaction terms to offset the negative effect. The 
interaction term will be "income level* educational level". It is a "dummy times dummy" type of interaction term. In our research, I decided to put in four interaction terms, they are "low income level* low educational level" (Incedu11 = Inc1 $\cdot$ Edu1), "low-income level* mid educational level" (Incedu12 = Inc1 $\cdot \boldsymbol{E d u 2})$, "mid income level* mid educational level" (Incedu22 = Inc2 $\cdot \boldsymbol{E d u 2})$, and "mid income level* high educational level" $($ Incedu23 $=\boldsymbol{I n c 2} \cdot \boldsymbol{E d u 2 3})$, There are originally 6 combinations for three income levels and three educational levels, however I have only picked four of them to avoid perfect multi-collinearity.

$P_{r}\left(Y_{i}=1\right)$

$$
\begin{aligned}
& =\Phi \\
& \left(\beta_{0}+\beta_{1} \text { Inc1 }_{i}+\beta_{2} \text { Inc2 }_{i}+\beta_{3} E_{\text {Eu1 }}+\beta_{4} E d u 2_{i}+\beta_{5} \text { Age }_{i}+\beta_{6} \text { Age }_{i}+\beta_{7} \text { Sex }_{i}+\beta_{8} M R S_{i}\right. \\
& \left.+\beta_{9} \text { Alch }_{i}+\beta_{10} \text { Incedu11 }_{i}+\beta_{11} \text { Incedu12 }_{i}+\beta_{12} \text { Incedu22 }_{i}+\beta_{13} \text { Incedu23 }_{i}+u_{i}\right), i \\
& =1,2,3 \ldots
\end{aligned}
$$

Note: $\quad$ Incedu $11=\operatorname{Inc} 1 *$ Edu $1 ;$ Incedu22 $=\operatorname{Inc} 2 * E d u 2 ;$

Incedu $12=$ Inc $1 * E d u 2 ;$ Incedu $23=$ Inc $2 *$ Edu 3

Column (3) shows the result of the probit regression with four interaction terms added. Our estimation results from column (3) imply that the effect of a specific income level that you are in on the smoking behavior will decrease if you are in a higher educational level. Let us consider an elder single woman (means all other control variables is 0 ). We can find that the coefficient of the interaction term "low-income level* low educational level" Incedu11 $=-\mathbf{0 . 0 8 8 8}$. That means if we acknowledge that a person belongs to a low-income level $(\boldsymbol{I n c}=\mathbf{1})$, the effect of low-income level on the probability to smoke depends on whether he/she belongs to the low educational level. If the person does belong to the low educational level $(\boldsymbol{E} \boldsymbol{d} \boldsymbol{u}=\mathbf{1})$, the Z-value will decrease by 0.0888 , and the probability will be $22.06 \%$. Similarly, if a person has medium educational level $(\boldsymbol{E} \boldsymbol{d u} \mathbf{2}=\mathbf{1})$, the Z-value will decrease by more, and the probability is $11.51 \%$. Within the same income group, if educational level is higher, the probability to smoke will decrease by more, since $-0.223<-.0888$. In other words, the promoting effect of low-income level on probability to smoke weakens due to a higher educational level.

Comparing to the coefficients in the expanded model without interaction terms, the coefficients in the model with interaction terms increases, so the original coefficients for low-income level, low educational level and mid educational level has been undervalued. However, because not every coefficient is statistically significant under $95 \%$ significance, I can only explain the effects of some of the interaction terms.

\section{Conclusion and Policy Advices}

In this research, I generally want to inspect the causal relationship between an individual's socioeconomic status and his/her smoking behavior. To be concrete, I mainly focused on a person's income and educational level to measure the socioeconomic status.

The research results matched my initial idea. In the benchmark model, income has a strong negative causal impact on a person's probability to smoke, which indicates that tobacco is an inferior good overall. Then, in the expanded model I also find that the probability to smoke will decrease as a person receives more education. Finally, when I add the interaction terms, I realize that within the same income level, if educational level is higher, the probability to smoke will decrease by more.

For other demographics, the findings in age are consistent with the original life-cycle hypothesis, 
which indicate a hump-shaped relationship between age level and probability to smoke. Elder people prefer more health consumption than tobacco consumption when they are getting older, facing with more and more severe health issues. However, younger people enjoy more cigarettes because their health risks are not that urgent, and they usually burden more stress of life.

Although from this research, I tried to eliminate the omitted variable bias by adding educational levels, the estimates of income may still be biased as there are some other exogenous factors that will cause an omitted variable bias, such as which kinds of neighborhood a person lives in. From the literature review, I know that tobacco advertisement is more prevalent in low-income neighborhoods (Humphreys, 2008). Therefore, the type of your neighborhood will be a determinant of smoking behavior and is correlated to your income level.

I have also found that the Pseudo- $\mathrm{R}^{2}$ is still low in this model. Therefore, I may need to introduce more control variables, such as the tobacco taxation, the price of tobacco, peers' behavior on smoking and the local smoking attitude, to improve the model. To investigate the mentioned above, for those variables can't be observed easily, we can resort to a panel data to solve it in the future study.

\section{Policy Advices}

According to the findings and conclusions, this research can suggest the government to lower taxes to increase an individual's disposable income, and their probability to smoke will decrease, also their probability of smoking cessation will go up, since tobacco is an inferior good. The government can also fund educational prevention programs to increase a person's educational level to lower the probability to smoke.

\section{Taxation approach:}

Based on what we have discussed beforehand, an overall taxation, such as accumulative wage tax, commodity tax, financial asset income tax, etc., can be reduced to promote people's overall income level. From an income enhancement, people will receive fewer living pressure and care more about their own healthy conditions. They will also find some healthier substitutes to relieve themselves, such as a gym membership, music, social activities and travels, etc. Until the implementation of a tax reduction, a household may not afford those healthier and more expensive habits, or they will make an excuse of having no time (actually lack money). The lost taxation can be compensated by a heavier tax imposed on the tobacco industry.

However, too heavy tax burdens may kill the tobacco companies and shrink the tobacco market, which eventually lead to a tax revenue reduction (and a declining in GDP, which is not desirable for the government). What's more, an insufficient tobacco supply will also lead to the repugnance and resistance of the public and the protest of the tobacco industry as well. Black markets for tobacco will also emerge in this case, which will finally lead to the failure of taxation approach. How to tradeoff really need the wisdom of the government.

\section{Education approach:}

Improving the educational level of the citizens is the best way to reduce tobacco use in the long run, for it can elevate the income level without the distortion of taxation. Educational improvement can also make people know better about the negative effect of smoking and their life-cycle decisions. Higher educational background will also provide people with a better circumstance being far away from some bad habits like smoking, and also provide people with better opportunities to supersede smoking habit. However, education level cannot be changed in a day, it always takes many years to be effective, which is the biggest defect of this approach. 
Other than educational improvement in an academic way, public moral education is crucial as well, and has considerable effect on controlling smoking behavior. This seems working and effective now.

\section{Tobacco quota approach:}

A simplest way to control the overall tobacco use is to control the quantity supplied, and the quantity that can be consumed by an individual. People must purchase tobacco with their valid ID. However, firms always have incentives to infract the production limit regulation, and individuals will always find ways to smoke beyond the standard. What's more, a sweeping approach over tobacco consumption will be too arbitrary: the quota for non-smokers will be wasted. Same as taxation approach, a quota approach will also lead to significant illegal transaction problems. In this case, maybe a tradable tobacco use permit will be a better way to solve this problem, letting the market to decide the real cost of smoking. However, the biggest problem in this approach is the difficulty of implementation on such an enormous number of objects. The policy implementation and maintaining cost will be huge.

\section{Mixed approach:}

Finally, in the end of this paper, I want to suggest a mixed approach in controlling the tobacco use. In this approach, government endows tax credits to different income groups: for lowest income group, a highest tax credit will be given to them. For higher income group, this tax credit will gradually phase out. For taxation on tobacco industry, the government can impose heavy commodity tax on tobacco products and production tax on tobacco production at first, and then gradually phase out this taxation overtime. This process may last for several years, even a decade, in purpose of waiting for the effect of the education approach comes into power. Because of the increased income level and higher prices of tobacco products, people will change their preferences overtime under the influence of enhancing educational level.

Government can also establish an assistant big data system to collect demographic information, and decides the tax credit allocation base on that. For example, for elder people the tobacco tax credit will be lower, and for mid-aged man the tax credit will be higher. Moreover, government can also impose different tobacco commodity tax based on different age groups and income groups. A midaged low-income man will be taxed the most on tobacco consumption, while he will receive a higher tax credit at the same time. In this case, both income effect and substitution effect will lead to a less tobacco consumption, considering tobacco is an inferior good.

This method can offset part of the disadvantages of the taxation approach and use the tax distortion in a more precise and delicate way, and the tobacco firms won't be taxed forever to their doom. Government can even use subsidies to balance the negative effect of tobacco taxations.

All in all, if the economic tool mentioned above can be veritably effective and feasible, then the tobacco consumption and the smoking behavior can be restrained. As a result, the smoking related financial costs and healthy costs can be alleviated significantly. Meanwhile, if the mixed approached can truly mitigate part of the negative effects from the tax distortion, then the tobacco industry will suffer less from the policy. If this consequence really come true, then the overall wellbeing of the citizens and the economy will all benefit from the policy, which will be another example for the wisdom of economics outwit the 'second best world'. 


\section{References}

[1] Adshade, M. (2014, November 11). Want to smoke less? Get married. The Globe and Mail. Retrieved April 05, 2017, from: http://www.theglobea ndmail.com/opinion/want -to smoke-lessget-married/article15348156/

[2] Benson, E., Kuipers, M. A. G., Nierkens, V., Bruggink, J. W., Stronks, K. \& Kunst, $\quad$ E. (2015). Socioeconomic inequalities in smoking in The Netherlands before and during the Global Financial Crisis: a repeated cross-sectional study. BMC Public Health. doi:10.1186/s 128 89-015-1782-6

[3] Bradley, S. (2015). Health study shows economic burden of smoking, overeating, inactivity. CBC, from: http://www.cbc.ca/news/canada/nova-scotia/health-study-shows-economi cburden- of-smoking-overeating-inactivity-1.3190141/

[4] Canadian Cancer Society's Advisory Committee on Cancer Statistics. (2014). Canadian Cancer Statistics 2014. Toronto, ON: Canadian Cancer Society; 2014. ISSN 083 5-2976/

[5] Canadian Cancer Society. (n.d.). Smoking and Cancer. Retrieved from: http://www.cancer.ca/en/prevention-and-screening/live-well/smoking-and-tobacco/smokingand-cancer/?region $=$ on

[6] Cummins, R.O., Shaper, A. G., Walker, M.\& Wale, C. J. (1983). Smoking and drinking by middle-aged British men: effects of social class and town of residence. Epidemiology and Community Health, 1983, 37, 249-255.

[7] Drobes, J. (2002). Concurrent Alcohol and Tobacco Dependence Mechanisms and Treatment. National Institute of Alcohol Abuse and Alcoholism. Retrieved April 05, 2017, from: https: //pubs.niaaa.nih.gov/publications/arh26-2/136-142.htm

[8] Health Retreat Centers. (2014). Cost of Smoking - Statistics, Cost Calculator. Retrieved April 05, 2017, from: https:/www.healthretreat.ca/cost-smoking-statistics-cost-calcul ator/

[9] Hitchman, S.\& Fong, G. (2011). Gender empowerment and female-to-male smoking prevalence ratios. Bulletin of the World Health Organization 2011, 89:195-202.

[10]Humphreys, K. (2015). Why the wealth stopped smoking, but the poor didn't. The Washinton Post. from: https://www.washingtonpost.com/news/wonk/wp/2015/01/1 4/why-the-wea lthystopped-smoking-but-the-poor- di dnt/?utm_term=.be $849813 \mathrm{a} 8 \mathrm{db}$

[11]Koning, P., Webbink, D., and Martin, G. (2015). The effect of education on smoking beha- vior: New evidence from smoking durations of a sample of twins. Empirical Economic, 48(4): 147997. 
[12]Peck, R. (2002). Equity Issues, Tobacco, and the Poor. The World Bank Economics of Tobacco Toolkit. Retrieved April 05, 2017, from: http://documents.worldbank.org/ curated/en/110921468339597503/Equity-Issues-tobacco-and-the -poor

[13]Smoking and Lung Cancer in Canada. (2010) .Canadian Partnership Against Cancer. Retrieved from: http://www.cancercare.ns.ca/sitecc/media/cancercare/smoking\%20in\%20canada.pdf

[14] Statistics Canada. (2014). Canadian Income Survey, 2014. Retrieved April 05,2017, from: http://www.statcan.gc.ca/daily-quotidien/160 70 8/dq16 0708b -eng.htm

[15] Statistics Canada. (2014). Female Population [2014] (89-503X201500114152). Retrieved April 05, 2017, from: http://www.statcan.gc.ca/pub/89-503-x/2015001/article/14152 -eng.htm

[16]The American Heritage ${ }^{\circledR}$ New Dictionary of Cultural Literacy. Socioeconomic status, 3rd ed., s.v. Retrieved April 05, 2017, from: http://www.dictionary.com/browse/soci oeconomic-status s.v.

[17] Tobacco Free Maine, (2008). Socioeconomic Status: The Single Greatest Predictor of Tobacco. Retrieved April 05, 2017, from: http:/www.tobaccofre ema in e.org/channe ls/special_populations/lowincome_and_education.php

[18]Walque, D. (2006). Does education affect smoking behaviours? Evidence using the Vietnam draft as an instrument for college education. Journal of Health $\quad$ Economics. (Vol.26, Issue 5.p.87 7-895). Retrieved from:

http://doi.org/10.1016/j.jhealeco.2006.12.005

[19]West, P., Sweeting, H.\& Young, R. (2015). Smoking in Scottish youths: personal income, parental social class and the cost of smoking. PubMed, 16(5): 329-335. doi: $10.1136 /$ tc. 2006.018721

[20]WHO, (2015). WHO Report on the Global Tobacco Epidemic. (pp. 16-20). Retrieved April 05, 2017, from: http://www. who.int/tobac co/global report/2015/report/en/

[21]WHO, (2015). WHO Report on the Global Tobacco Epidemic. (pp. 186). Retrieved April 05, 2017, from: http://www. who.int/tobac co/global report/2015/report/en/

[22] Workopolis, (2016). So, how much are we earning? The average Canadian salaries by industry and region. Retrieved April 05, 2017, from: http://careers.workopolis.com/advice/how-muchmoney-are-we-earning-the-average-canadian-wages-right-now/

[23]Young Kyung Do. \& Bautista, M. (2015). Tobacco use and household expenditures on food, education, and healthcare in low- and middle-income countries: A multilevel analysis. Bmc Public Health, 15(1): 1098. 